\title{
AS POLÍTICAS AFIRMATIVAS NO ENSINO SUPERIOR E O DESENHO INSTITUCIONAL DE JUSTIÇA COMO EQUIDADE EM RAWLS
}

\author{
LAS POLÍTICAS AFIRMATIVAS EN LA ENSEÑANZA SUPERIOR Y EL DISEÑO \\ INSTITUCIONAL DE JUSTICIA COMO EQUIDAD EN RAWLS
}

\author{
THE AFFIRMATIVE POLICIES IN HIGHER EDUCATION AND THE \\ INSTITUTIONAL JUSTICE DRAWING AS EQUITY IN RAWLS
}

\author{
Paulo Fernando de Melo MARTINS ${ }^{1}$ \\ Maurício Dias dos SANTOS ${ }^{2}$
}

RESUMO: Este artigo resultou de debates e pesquisas no Núcleo Interdisciplinar de Educação em Direitos Humanos da Universidade Federal do Tocantins sobre políticas de acesso e permanência no ensino superior. Analisou o resultado da política de cotas no perfil discente das universidades federais sob a luz rawlsiana de justiça. As reflexões recorreram aos dados da IV Pesquisa Nacional sobre o Perfil Socioeconômico e Cultural dos Graduandos das Instituições Federais de Ensino Superior, da Associação Nacional dos Dirigentes das Instituições Federais de Ensino Superior com o Fórum Nacional de Pró-reitores de Assuntos Comunitários e Estudantis. Referenciando-se no princípio da diferença, conclui que para operar de maneira efetiva e em plenitude na concretização da justiça social, medidas de ação afirmativa não devem apenas prever a discriminação positiva sobre um viés único, que no caso das cotas para o ensino superior almeja somente a questão do acesso sem garantir condições adequadas de permanência.

PALAVRAS-CHAVE: Ensino superior. Ações afirmativas. Cotas raciais. Rawls.

RESUMEN: Este artículo resultó de debates e investigaciones en el Núcleo Interdisciplinario de Educación en Derechos Humanos de la Universidad Federal de Tocantins sobre políticas de acceso y permanencia para educación superior. Analizó el resultado de la política de cuotas en el perfil discente de las universidades federales bajo la luz rawlsiana de justicia. Las reflexiones recurrieron a los datos de la IV Investigación Nacional sobre el Perfil Socioeconómico y Cultural de los Graduandos de las Instituciones Federales de Enseñanza Superior, de la Asociación Nacional de los Dirigentes de las Instituciones Federales de Enseñanza Superior y del Foro Nacional de Pro-rectores de Asuntos Comunitarios y Estudiantiles. Al referirse al principio de la diferencia, concluye que para operar de manera efectiva y en plenitud en la concreción de la justicia social, medidas de acción afirmativa no sólo deben prever la discriminación positiva sobre un sesgo único, que en el caso de las cuotas para la enseñanza superior anhela sólo la cuestión del acceso sin garantizar condiciones adecuadas de permanencia.

${ }^{1}$ Universidade Federal do Tocantins (UFT), Palmas - TO - Brasil. Coordenador do Departamento Interdisciplinar de Educação em Direitos Humanos. ORCID: <https://orcid.org/0000-0003-3551-8363>. E-mail: paulofernando@mail.uft.edu.br

${ }^{2}$ Universidade Federal do Tocantins (UFT), Palmas - TO - Brasil. Departamento Interdisciplinar de Educação em Direitos Humanos. ORCID: <https://orcid.org/0000-0003-3551-8363>. E-mail: paulofernando@mail.uft.edu.br 
PALABRAS CLAVE: Enseñanza superior. Acciones afirmativas. Cotas raciales. Rawls.

ABSTRACT: The article resulted from debates and research in the Interdisciplinary Nucleus of Human Rights Education of the Federal University of Tocantins on policies of access and permanence in higher education. He analyzed the result of the quota policy in the student profile of federal universities in the light of Rawlsian justice. The reflections drew on data from the IV National Survey on the Socioeconomic and Cultural Profile of the Graduates of the Federal Institutions of Higher Education, the National Association of Leaders of the Federal Institutions of Higher Education with the National Forum of Pro-rectors of Community and Student Affairs. Referring to the principle of difference, he concludes that to operate effectively and fully in the realization of social justice, affirmative action measures should not only provide for positive discrimination on a single bias, which in the case of quotas for higher education only the issue of access without ensuring adequate conditions of permanence.

KEYWORDS: Higher education. Affirmative actions. Racial quotas. Rawls.

\section{Introdução}

O estudo das desigualdades tem multiplicado a produção científica nos últimos anos. Uma variedade de pesquisas sobre disfunções de renda, educação, raça, gênero, além de outras, vêm sendo produzidas no sentido de investigar as razões e consequências da estratificação social hodierna (SCALON; SALATA, 2016). O tema está longe do esgotamento, sobretudo visto a importância de desvelar fatores influentes dessas dessemelhanças na estrutura social, cada vez mais dinâmica.

As cotas para ingresso no ensino superior público é exemplo de política cujo propósito é mitigar as contingências sociais. Estudar seu impacto na constituição do perfil acadêmico universitário tende a demonstrar o resultado prático desse tipo de política, em especial no contexto interno das universidades (VASCONCELOS; GALHARDO, 2016). Este trabalho é uma completude para demais pesquisas de mesma temática, assim, subsidiando a formulação de políticas de equidade mais consistentes.

Nesse sentido, o objetivo foi analisar o impacto da política de cotas na configuração do perfil discente das universidades federais, sob a perspectiva rawlsiana de justiça como equidade. Para tanto, além de textos normativos e demais conteúdos bibliográficos, também foram utilizados dados oriundos da IV Pesquisa Nacional sobre o Perfil Socioeconômico e Cultural dos Graduandos das Instituições Federais de Ensino Superior (ANDIFES, 2016). Essa compreensão permite não apenas a justificação de ações e programas de inclusão, mas como 
também contribui para apresentar soluções viáveis e efetivas, em especial para as políticas de assistência estudantil.

\section{Metodologia}

O Perfil Socioeconômico e Cultural dos Estudantes de Graduação das Instituições Federais de Ensino Superior (Ifes) é um trabalho da Associação Nacional dos Dirigentes das Instituições Federais de Ensino Superior (Andifes), em parceria com Fórum Nacional de PróReitores de Assuntos Estudantis (Fonaprace). Reuni características socioeconômicas e culturais dos estudantes de graduação das universidades federais, realizado a cada quatro anos. É uma continuidade de estudos anteriores, sendo a quarta edição uma atualização implementada em 2014.

Como a política de cotas passa a vigorar somente em 2013, o comparativo mais próximo é a terceira edição, isto é, a pesquisa de 2010. Outro fator que merece ser mencionado é que cuida de uma pesquisa abrangente, que cobre dados para além daqueles utilizados como critério na definição dos contemplados como cotistas, que são exclusivamente renda e pertencimento a grupo racial e étnico. Nesse sentido, as informações aquém dos aspectos contemplativos do estudante cotista foram deixadas de lado, privilegiando um conjunto de dados mais específico.

O público alvo foi composto por estudantes de graduação de 62 instituições participantes da pesquisa. Os dados foram coletados no final do semestre de 2014 e no início de 2015. Conta com uma amostra de 939.604 graduandos, com informações tipo perfil básico, moradia, família, trabalho, histórico escolar, vida acadêmica, informações culturais, saúde e qualidade de vida, e dificuldades estudantis.

Tendo em vista o desenho institucional da Lei das Cotas, sobretudo sua pretensão principal, que é democratizar o acesso à educação superior, foi observado o perfil dos graduados segundo os critérios contemplativos do estudante cotista, quais sejam: oriundo do ensino médio público, renda familiar e grupo étnico ou racial. Dessa forma, foi possível observar em que medida a política de cotas vem contribuindo para democratizar o ensino superior público e se o resultado conferido é compatível/justificável com a concepção rawlsiana de justiça como equidade.

\section{Perfil Socioeconômico e Cultural dos Graduandos}


Os dados utilizados estão divididos segundo a distribuição das vagas pela Lei 12.711 . Os critérios distributivos que essa legislação prever são decisivos para a definição dos seguimentos sociais contemplados. Regulamenta o acesso à graduação nas universidades e institutos federais de ensino, dizendo que em cada concurso seletivo para ingresso nos cursos de graduação, serão reservadas no mínimo $50 \%$ das vagas a estudantes que tenham cursado integralmente o ensino médio em escolas públicas. Na figura abaixo, o fluxograma demonstra de maneira mais clara como estar sistematizado o sistema de cotas nela previsto.

Figura 01 - Distribuição de vagas segundo a Lei 12.711/2012

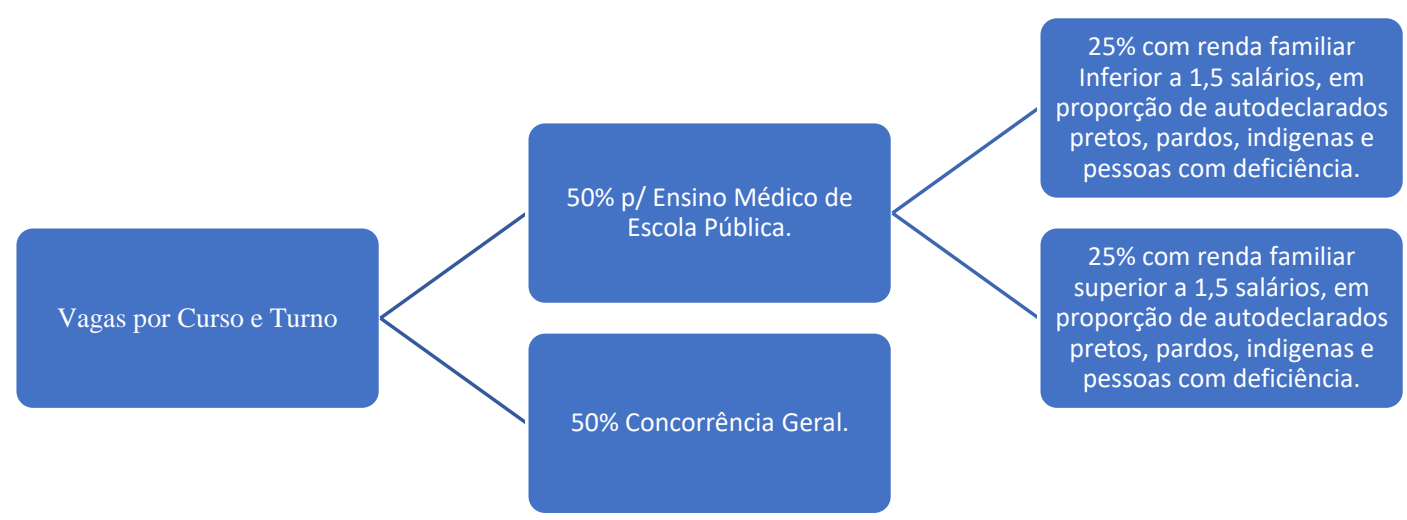

Fonte: Feita pelos autores

\section{Graduandos Segundo Escola de Ensino Médio}

Tabela 1 - Tipo de escola que cursaram o ensino médio, por faixa de ingresso.

\begin{tabular}{|c|c|c|c|c|c|c|c|}
\hline $\begin{array}{l}\text { Tipo de escola } \\
\text { Médio }\end{array}$ & Ensino & & 2009-menos & 2010-2011 & 2012-2013 & 2014-2015 & Total \\
\hline Somente & escola & Freq. & 51.843 & 148.914 & 219.795 & 144.729 & 565.281 \\
\hline pública & & $\%$ & 49,99 & 58,16 & 61,82 & 64,53 & 60,16 \\
\hline Maior parte em & escola & Freq. & 5.210 & 9.926 & 13.455 & 7.710 & 36.301 \\
\hline pública & & $\%$ & 5,02 & 3,88 & 3,78 & 3,44 & 3,86 \\
\hline Maior parte em & escola & Freq. & 5.541 & 11.964 & 15.577 & 9.104 & 42.185 \\
\hline particular & & $\%$ & 5,34 & 4,67 & 4,38 & 4,06 & 4,49 \\
\hline Somente & escola & Freq. & 41.121 & 85.250 & 106.736 & 62.730 & 295.837 \\
\hline particular & & $\%$ & 39,65 & 33,29 & 30,02 & 27,97 & 31,49 \\
\hline & & Freq. & 103.715 & 256.054 & 355.562 & 224.273 & 939.604 \\
\hline & & $\%$ & 100 & 100 & 100 & 100 & 100 \\
\hline
\end{tabular}

Fonte: CEPES/UFU. Pesquisa Perfil do Graduando IFES - 2015.

Nota: Tabela modificada pelo autor.

Os que cursaram o ensino médio somente em escola pública na faixa de 2014-2015 representavam pouco mais de $64,5 \%$ dos estudantes de graduação. Seguido daqueles que 
estudaram integralmente em escolar particular, que totalizavam cerca de $28 \%$. Posteriormente estão os que fizeram maior parte em escola particular, e por fim, se mostram os que estudaram maior parte em escola pública, com pouco mais de $3 \%$. Conclui que houve um crescimento considerável de estudantes oriundos da escola pública na educação superior nos últimos anos.

\section{Graduandos segundo renda per capita bruta}

Tabela 2 - Graduando segundo renda familiar per capita bruta: 2010 a 2014

\begin{tabular}{llll}
\hline Faixas salariais & & $\mathbf{2 0 1 0}$ & $\mathbf{2 0 1 4}$ \\
\hline \multirow{2}{*}{ Não tem renda } & números absolutos & 2.953 & 9.969 \\
& população brasileira \% & - & 1 \\
& graduando \% & 0,45 & 1,1 \\
\hline \multirow{3}{*}{ Até 1 Salário } & números absolutos & 51.706 & 114.116 \\
& população brasileira \% & - & 10,8 \\
& graduando \% & 7,8 & 12,2 \\
\hline \multirow{3}{*}{ Mais de 1 a 2 salários } & números absolutos & 119.029 & 220.229 \\
& população brasileira \% & - & 21,5 \\
& graduando \% & 18,1 & 23,4 \\
\hline \multirow{2}{*}{ Mais de 2 a 3 salários } & números absolutos & 93.110 & 138.870 \\
& população brasileira \% & - & 18,1 \\
& graduando \% & 14,1 & 14,7 \\
\hline \multirow{2}{*}{ Mais de 3 a 5 salários } & números absolutos & 117.125 & 170.756 \\
& população brasileira \% & - & 21,2 \\
& graduando \% & 17,8 & 18,2 \\
\hline \multirow{2}{*}{ Mais de 5 a 10 salários } & números absolutos & 162.402 & 186.089 \\
& população brasileira \% & - & 15,9 \\
& graduando \% & 24,7 & 19,8 \\
\hline \multirow{2}{*}{ Mais de 10 salários } & números absolutos & 109.711 & 99.574 \\
& população brasileira \% & - & 11,2 \\
& graduando \% & 16,7 & 10,6 \\
\hline Total & & 656.167 & 939.604 \\
\hline
\end{tabular}

Fonte: CEPES/UFU. Pesquisa Perfil do Graduando IFES - 2015.

Nota: tabela modificada pelo autor

Em relação ao rendimento mensal familiar bruto, se constata que entre 2010 e 2014, houve uma evolução na proporção de estudantes que não tem renda. No primeiro ano eram 0,45\%; já no segundo salta para 1,1\%; aumento de 0,61\%. Em números absolutos significou um acréscimo de 7.016 estudantes. Na composição populacional, esse dado se reflete em similaridade em 2014.

Aqueles com renda de até 1 salário mínimo em 2010 eram 7,8\%; e em 2014 saltou para $12,2 \%$. Aqui também se constata uma evolução, com variação de aumento de 4,8\%. Em relação 
à composição populacional, em 2014 esse público representava 10,8\%; uma diferença de 1,4\% com o perfil acadêmico.

Os que estão na faixa de mais de 1 até 2 salários, em 2010 eram 18,1\%; em 2014 esse número acentuou para 23,4\%. Ou seja, uma evolução de 5,3\% para mais. Comparado com a composição populacional, houve uma variação positiva de $1,9 \%$.

Em relação aos que tem renda mais de 2 até 3 salários, no ano de 2010 representavam 14,1\%; quanto que em 2014 já eram 14,7\%. Se percebe uma acentuação pouco expressiva, de apenas $0,6 \%$. A composição social desse grupo, entretanto, é maior, sendo $18 \%$ da população brasileira, variando em -3,4\% comparada à representação acadêmica.

A terceira faixa de renda, que é mais de 3 a 5 salários, em 2010 eram 17,8 dos estudantes de graduação; passando a compreender 18,2\% em 2014. A representação desse grupo na graduação superior, comparada à sua composição social é -3,1.

Já os que tem mais de 5 e até 9 salários, em 2010 representavam 24,7\% dos estudantes de graduação, em 2014 decresceu para 19,8\%. Sua representação estudantil comparada à composição social, entretanto, ficou positiva em 3,9\%. Por fim, os que tem renda familiar bruta acima de 10 salários representavam em 2010 16,7\% dos graduandos. Já em 2014, esse número decaiu para 10,6\%. A representação estudantil desse grupo em relação sua composição na sociedade ficou em $-0,7$.

Tabela 3 - Classes econômicas dos graduandos Ifes e da população brasileira

\begin{tabular}{lcclll}
\hline Classificação econômica & A (\%) & B (\%) & $\mathbf{C ~ ( \% ) ~}$ & D+E (\%) & C+D+E (\%) \\
\hline Graduandos Ifes 2010 & 15,3 & 41,1 & 33,6 & 10,1 & 43,7 \\
\hline Graduandos Ifes 2014 & 7,7 & 40,2 & 43,5 & 8,6 & 52,1 \\
\hline População brasileira 2014 & 2,7 & 23,1 & 47,5 & 26,6 & 74,1
\end{tabular}

Fonte: CEPES/UFU. Pesquisa Perfil do Graduando IFES - 2015.

Nota: Tabela modificada pelos autores.

Em relação à constituição de classes econômicas, percebe-se uma diminuição na representatividade de estudantes das classes A e B, que demonstra um caimento de $7 \%$ e $1 \%$, respectivamente. Outra ponta ver-se consideravelmente aumentar a representatividade das classes C, D e E. A despeito do aumento dos índices de representação, também é notável que essas classes ainda são percentualmente a larga maioria da população.

\section{Composição segundo dados de cor/raça}


Tabela 4 - Graduandos segundo raça/cor - 2010 a 2014

\begin{tabular}{clll}
\hline Cor ou Raça & Pesquisa & $\mathbf{2 0 1 0}$ & $\mathbf{2 0 1 4}$ \\
\hline \multirow{2}{*}{ Amarela } & IFES & 3,06 & 2,34 \\
& PNAD/Censo & 1,09 & 0,49 \\
\hline \multirow{2}{*}{ Branca } & IFES & 53,93 & 45,67 \\
& PNAD/Censo & 47,73 & 45,48 \\
\hline \multirow{2}{*}{ Parda } & IFES & 32,08 & 37,75 \\
& PNAD/Censo & 43,13 & 45,05 \\
\hline \multirow{2}{*}{ Preta } & IFES & 8,72 & 9,82 \\
& PNAD/Censo & 7,61 & 8,58 \\
\hline \multirow{2}{*}{ Indígena } & IFES & 0,93 & 0,64 \\
& PNAD/Censo & 0,43 & 0,4 \\
\hline \multirow{2}{*}{ Outra } & IFES & 1,28 & - \\
& PNAD/Censo & - & - \\
\hline \multirow{2}{*}{ Sem decl. } & IFES & - & 3,78 \\
& PNAD/Censo & 0 & 0 \\
\hline
\end{tabular}

Fonte: CEPES/UFU. Pesquisa Perfil do Graduando IFES - 2015.

Tabela 5 - graduandos segundo cor/raça números absolutos

\begin{tabular}{lcc}
\hline Cor ou Raça & $\mathbf{2 0 1 0}$ & $\mathbf{2 0 1 4}$ \\
\hline Amarela & 20.079 & 21.977 \\
\hline Branca & 353.871 & 429.149 \\
\hline Parda & 210.498 & 354.688 \\
\hline Preta & 57.218 & 92.240 \\
\hline Indígena & 6.102 & 6.014 \\
\hline Outra & 8.399 & \\
\hline Sem declaração & & 35.536 \\
\hline Total & $\mathbf{6 5 6 . 1 6 7}$ & $\mathbf{9 4 1 6 1 8}$ \\
\hline
\end{tabular}

Fonte: CEPES/UFU. Pesquisa Perfil do Graduando IFES - 2015.

De 2010 a 2014 as mudanças em termos de cor/raça foram bastante significativas. Os autodeclarados amarelos decresceram 0,72\%; referente ao total absoluto de alunos. Entretanto, o grupo também sofreu redução na composição social do país em $0,6 \%$. Dessa forma, ainda se acham acentuadamente representados na educação superior, vez que seu número na composição social continua sendo bem mais inferior, ou seja, 2,34\% dos estudantes de graduação e são $0,49 \%$ da população.

Em relação aos brancos também houve decréscimo, de 8,26\%. Nesse grupo também se observa que não houve prejuízo de representação na educação superior, posto que a variação com a composição social se manteve em similaridade. Representam 45,67\% dos estudantes de graduação e são 45,48\% da população.

Os pardos conseguiram aumentar seu grau de representação na graduação da educação superior. Em 2010 eram 32,08\% do total de estudantes, e em 2014 são 37,75\%, ou seja, uma 
elevação de 5,67\%. Entretanto, em relação à composição social, ainda são inferiorizados, posto que representam $45,05 \%$ da população, percentual de $7,3 \%$ maior que a representação escolar descrita acima.

Os autodeclarados de cor preta também aumentaram a representação na educação superior. Em 2010 eram 8,72\%, elevando esse número para 9,82\% em 2014, diferença de 1,1\%. Nesse caso, a representação desse grupo no ambiente escolar da graduação no ensino superior se manteve homogênea em relação sua representatividade na composição social, com uma variação de $0,14 \%$ para mais.

Já em relação aos indígenas houve um decréscimo no número de estudantes. Em 2010 eram $0,93 \%$ e em 2014 esse número cai para 0,64\%. A representação desse grupo na graduação superior comparada com sua representação demonstra-se acentuada se comparada a composição social, que é de 0,4 em 2014.

\section{Formulação da Justiça como Equidade em Rawls}

A ideia central de Rawls foi, no âmbito da filosofia moral e política, desenvolver uma teoria de justiça que fosse uma alternativa viável ao predomínio do utilitarismo (LOVETT, 203, p. 11). É opondo sobre essa doutrina que desenvolveu uma concepção original de justiça, ou seja, no contexto de uma afirmação teórica que se apresentava incompleta do ponto de vista das instituições morais modernas. Para tanto, parte de duas ideias fundamentais. A primeira faz supor que a sociedade é um empreendimento cooperativo regido por regras, cujo objetivo é ampliar o bem de quem dele participa. A segunda diz sobre a estrutura social básica, que é a maneira como as instituições mais importantes estão arranjadas para fundamentar práticas políticas, econômicas, legais e culturais, que em último caso, determinam a divisão dos benefícios a partir da colaboração social (RAWLS, 2016, p. 08).

Sendo a sociedade um sistema de cooperação de benefício mútuo, e sua estrutura básica como produtora das regras fundamentais de colaboração, por conseguinte, é possível pensar uma teoria de justiça social que lhe fosse aplicável. A estrutura básica da sociedade, portanto, é o objeto da justiça (RAWLS, 2016, p. 08). O utilitarismo é a teoria segundo qual a estrutura social mais justa é aquela que tenderia a ampliar ao máximo a soma da felicidade geral de seus integrantes, considerando a felicidade individual de cada um de maneira igual. Nesse sentido, institutos como a escravidão e o sexismo seriam legitimados desde que o cômputo da somatória geral fosse benéfico para um maior número de pessoas. Decerto, esse não seria o instrumento 
mais adequado para dar conta de uma justiça social. Então seria necessário formular uma teoria melhor, mais completa, tarefa que o autor se propõe.

Intuitivamente a estrutura social mais justa é aquela que os indivíduos escolheriam, caso não soubessem o papel que cada um assumiria na conjuntura do sistema de cooperação. Aqui a ideia de contrato social é reformulada no sentido de trocar a escolha do governante, pela posição original de cada um sob um véu de ignorância - que tapa a possibilidade de visualização sobre a função social que cada um viria a ser na sociedade. Sem a possibilidade de ao menos ter expectativa do que viria assumir, racionalmente os membros da sociedade escolheriam uma estrutura social equitativa, em que todos compartilham das mesmas oportunidades (RALWS, 2016, p. 21).

Nesse sentido, provisoriamente, dois princípios de Justiça são formulados (RAWLS, 2016, p. 73):

Primeiro: cada pessoa deve ter um direito igual ao sistema mais extenso de iguais liberdades fundamentais que seja compatível com um sistema similar de liberdades para as outras pessoas.

Segundo: as desigualdades sociais e econômicas devem estar dispostas de tal modo que tanto (a) se possa razoavelmente esperar que se estabeleçam em benefício de todos como (b) estejam vinculadas a cargos e posições acessíveis a todos.

O segundo princípio apresenta duas expressões ambíguas: "benefício de todos" e “acessíveis a todos" (RAWLS, 2016, p. 73). Para uma definição mais precisa será necessário, uma segunda reformulação. Dessa forma, a estrutura básica da sociedade é dividida em duas partes, sobre as quais uma se aplica ao primeiro princípio e a outra ao segundo. Nesse sentido, dois aspectos fazem distinção, em que um define e garante as liberdades fundamentais e, o outro, específica e estabelece as desigualdades sociais e econômicas (RAWLS, 2016, p. 74) ${ }^{3}$.

O primeiro princípio diz que as liberdades fundamentais devem ser iguais, e o segundo se aplica à distribuição de riqueza e à estruturação de organizações que fazem uso de diferenças de autoridade e responsabilidade. Embora a distribuição de renda e riqueza não precise ser igual, deve ser vantajosa para todos e, ao mesmo tempo, os cargos de autoridade e responsabilidade devem ser acessíveis a todos. Aplica-se esse princípio mantendo-se abertos os cargos e, depois desse limite, dispondo as desigualdades sociais e econômicas de modo que todos se beneficiem deles (RALWS, 2016, p. 74).

Pressupondo que o primeiro princípio sempre esteja em primeiro lugar, liberdades fundamentais prevalecendo frente a quaisquer vantagens econômicas e sociais, chega-se a

${ }^{3}$ Liberdades fundamentais figuram em uma lista predefinida pelo autor - liberdade política (p.74). 
quatro maneiras distintas de intepretação, relevando quatro sistemas de justiça, quais sejam: sistema de liberdade natural, igualdade liberal, aristocracia natural e igualdade democrática (RALWS, 2016, p. 74-79).

O sistema de liberdade natural não se traduz em uma intepretação adequada. Nessa forma de pensar, a distribuição de bens e direitos estaria regulamentada por um arranjo de igualdade formal, em que a oportunidade de acesso estaria aberta aos talentos e capacidades naturais de cada um, conforme fossem aprimorados ou deixados de lado, a depender se o uso de tais vantagens fosse favorecido ou não por circunstâncias sociais e fortuitas. As parcelas de distribuição adstritas à influência desses fatores são consideradas arbitrárias do ponto de vista moral, porque criam contingências sociais específicas (RAWLS, 2016, p. 85-88).

O sistema de igualdade liberal tenta atenuar a influência dessas contingências sociais. Para tanto, impõe condições estruturais no arranjo institucional da sociedade que permitem a igualdade equitativa de oportunidades, seria o caso de oportunizar educação de qualidade destinada a todos. Essa interpretação muito embora possa parecer ser mais justa, também é falha, pois não elimina por completo fatores históricos e circunstâncias ocasionais de sorte e talento, especialmente sobre influência de questões tais como cultura e ambiente familiar, que contribuem para o amadurecimento em maior ou menor grau das aptidões naturais (RALWS, 2016, p. 88-89).

A aristocracia natural também é falha. Essa interpretação não pretende atenuar as contingências sociais da igualdade formal, ao contrário, as acentua e almeja limitar as vantagens dos que detém maiores capacidades naturais àqueles que promovem o bem dos setores mais pobres da sociedade. Seria dizer que os benefícios dos de maiores prestezas irradiam aos menos privilegiados. Aqui, da mesma forma que na interpretação anterior, não se estaria livre da influência de contingências sociais e do acaso natural na determinação das parcelas de distribuição e, portanto, é também inadequada segundo os preceitos morais (RALWS, 2016, p. 89-90).

A melhor intepretação é a da igualdade democrática. Ela conjuga o princípio da diferença com a igualdade equitativa de oportunidades. A ideia é que a expectativa dos que estão melhores situados na estrutura social somente se justifica se fizer parte de um esquema que venha a elevar também a expectativa dos menos privilegiados, em um contexto material de iguais oportunidades, ou seja, as desigualdades devem estar arranjadas de modo a beneficiar os membros menos favorecidos, para que tenham iguais ensejos de acesso aos bens e oportunidades (RAWLS, 2016, p. 90-100). 
Dessa forma, o segundo princípio da justiça como equidade é reformulado, e passa para a seguinte maneira:

As desigualdades sociais e econômicas devem estar dispostas de tal modo (a) propiciem o máximo benefício esperado para os menos favorecidos como (b) estejam vinculadas a cargos e posições abertos a todos em condições de igualdade equitativa de oportunidades (RAWLS, 2016, p. 100).

O princípio da diferença permite que na conjuntura da estrutura social de democracias liberais, as instituições propiciem ações no sentido de promover a representação de segmentos sociais discriminados. As políticas de ação afirmativa, tais como as cotas em razão de renda, raça, grupo étnico ou gênero, sem dúvida, são um exemplo cabal desse tipo de projeto, pois anseiam atenuar a influência das contingências socais e históricas, permitindo a distribuição igualitária às oportunidades de bens e direitos.

O grande trunfo da concepção de justiça de Rawls foi inaugurar um largo campo de debates, inclusive permitindo a reformulação de seus escritos ao longo dos anos. Desde que sua principal obra Uma Teoria de Justiça foi publicada em 1971, uma série de escritos foram concebidos num sentido de reconsiderar algumas posições importantes, sobretudo advindas de críticas contundentes de alguns aspectos em suas argumentações (LOVETT, 2013, p. 18).

Um ponto crítico a se destacar na concepção rawlsiana de justiça é a reformulação do contratualismo clássico. Apesar da evidente influência clássica, sobretudo de viés kantiano, desde logo fica claro tratar-se de uma fórmula original. Para que a ideia de justiça balizada nos pressupostos do contratualismo faça sentido, é necessário pensar uma posição de referência, nos mesmos termos tradicionais, em que os indivíduos mutuamente se reconhecem como cidadãos livres e iguais. A questão da posição original só pode ser imaginada a partir desse contexto, ou seja, da organização sociopolítica de uma sociedade liberal e democrática cujas bases do autorrespeito sejam intuitivas de seres racionais. Com efeito, há uma renovação do espírito contratual que passa da preocupação da estabilização política diante da pluralidade de sujeitos para o debate acerca das circunstâncias que tornam ou não as instituições legítimas diante de seus cidadãos (TREDANARO, 2018, p. 68-71).

Entretanto, a posição original não pode ser confundida com um estado de absoluta neutralidade, posto que lhe é inerente pressupostos prévios sobre princípios de justiça naturais mínimos. Para corrigir essa distorção, visto que tais pressupostos podem influenciar a decisão dos atores, Rawls propõe duas facetas. A primeira que a posição original seria um método para se chegar a um acordo sobre quais de tais princípios de justiça devem prevalecer em uma sociedade liberal democrática. De outro, trata-se de operação orientada a contextualizar as 
condições em que os sujeitos encontram-se ambientados. Diante dessa esquematização, intuitivamente se leva à indagação sobre o melhor arranjo social de justiça, concluindo a justiça como equidade e, nesse caso, a mais adequada (TREDANARO, 2018, p. 72).

É uma atitude de cautela de Rawls a caracterização da posição original como um estado hipotético de igualdade. Na medida em que se cuida de seres racionais, o poder de orientação de suas decisões é canalizado em interesses gerais, de ordem superior, não precisamente pensando em si mesmas. Noutro giro, as restrições que moldam a posição original - o véu da ignorância, a simetria das partes e a publicidade dos princípios de justiça -, envolvem a ideia de cooperação social, de cidadãos morais que se reconhecem como livres e iguais naquele primeiro momento. Dessa forma, a intenção é oferecer um método de seleção dos princípios mais adequados à estrutura social.

Contudo, o contrato é resultado de um contex to de compromisso não estático que pode variar ao logo do tempo por razões múltiplas de mudanças de interesses. Essa situação pode revelar que no decorrer do desenvolvimento social, a igualdade inicial não se assenta mais, visto as regras de livre mercado e demais posições socioculturais. É um problema na estabilidade dos termos contratuais, pois concepções diferentes de bem, em um determinado cenário, podem entrar em conflito com a concepção pública de justiça.

A solução é lutar por uma coerência entre os valores morais e a concepção pública de justiça adotada. No contexto democrático certamente os membros que compõe a estrutura social tende a apresentar-se sobre distintas filiações morais, sejam decorrentes de valores religiosos ou apenas configurados à determinada época (PETRONI, 2018, p. 147-152). Nesse sentido, seus membros devem aceitar-se livres e, sob um senso básico de racionalidade, observar as contingências sociais relevantes como incompatíveis com uma sociedade democrática e procurar de algum modo corrigi-las.

Outro ponto crítico a se destacar é que depois de firmada as bases de um acordo mútuo com base na ideia reformulada de contrato social, posteriormente, Rawls orienta o objeto da justiça como equidade. A estrutura básica da sociedade é a forma como as instituições sociais e políticas encontram-se arranjadas para determinar o sistema de cooperação, influenciando na divisão de bens e oportunidades. Sua configuração mais adequada é aquela que garante uma concepção de "justiça de fundo" (SILVEIRA, 2011, p. 205-206). Considerando que as relações pessoais vão sendo desenvolvidas ao longo do tempo a partir de acordos livres, inicialmente pactuados em status de real igualdade, o objetivo da estrutura básica é permitir condições de valores para que as ações individuais sejam efetivadas sem distorções morais inaceitáveis. 
A estrutura social justa é aquela que pessoas morais, livres e iguais adotariam caso estivessem em situação de efetiva igualdade. As partes na posição original não devem ter conhecimento das contingências sociais, função do véu da ignorância, no sentido de não o utilizar para determinar as escolhas sobre quais princípios de justiça adotar. Racionalmente, os princípios de justiça a serem escolhidos seriam iguais, quais sejam, as liberdades fundamentais, igualdade de oportunidade e o da diferença. O conteúdo da justiça, portanto, é escolhido pelo critério racional.

É nesse sentido que a estrutura básica deve permitir desigualdades desde que sejam benéficas para os menos favorecidos. Iguais liberdades fundamentais e condições equitativas de oportunidade operam juntas, incorporando um elemento fundamental de teoria de justiça procedimental, que é o princípio da diferença.

Em função desse raciocínio, chega-se à conclusão de que os princípios de justiça, em especial o da diferença, aplicam-se, no âmbito da esfera pública, às instituições que regem as desigualdades sociais e econômicas. Nessa direção, se devem estabelecer critérios para uma divisão não igual de bens primários, visando a eliminação contingencial, isto é, a mitigação das desigualdades existentes.

Todavia, é importante notar em que âmbito essas desigualdades são permissivas. A discriminação no trabalho e demais áreas importantes para o desenvolvimento de aptidões inatas, nessa perspectiva, somente atenta contra o princípio de igual nas oportunidades quando tem como efeito tornar substancialmente desiguais as chances de cidadãos com similares aptidões (ZANITELLI, 2015). Tais como candidatos a uma vaga de emprego, cujo perfil exige certo tipo de formação superior, nesse caso, a distinção se faz tendo como referência a qualificação profissional necessária ao bom desempenho laboral, os candidatos têm iguais oportunidades, mas estão nivelados à exigência no nível de escolaridade.

Já em relação ao princípio da diferença, a proibição à discriminação privada está relacionada ao bem primário das bases sociais do autorrespeito, e está adstrita aos casos de discriminação degradante, aquela cujo sentido expressivo é de negar o igual status moral das pessoas pertencentes a um certo grupo. Aqui, são os casos de distinção em relação a ser membro de um grupo marcado por características determinadas, seja em relação à renda, ao gênero, raça ou etnia. O critério, aqui, é baseado em definições originárias de fatores históricos e culturais específicos que os caracterizam em status de desigual cidadania (ZANITELLI, 2015).

Portanto, no contexto de sociedades liberais democráticas, em que a regras do livre mercado e o jogo das iguais liberdades fundamentais perante a lei tendem a criar desigualdades fáticas injustificáveis do ponto de vista moral, a justiça como equidade analisa o sistema de 
cooperação social a partir do status de igual cidadania entre seus membros. Caso se observe na estrutura social que há direitos básicos desiguais fundamentados em características específicas como renda, sexo ou cultura, por exemplo, essa distorção deve ser corrigida na medida em que confere dessemelhança no usufruto de bens primários, imprescindíveis à dignidade de todos.

Assim, o princípio da diferença opera observando se o modelo social permite o favorecimento de determinados membros em relação a outros, justificando tal desigualdade somente se for vantajosa para os menos favorecidos. Caso contrário, qualquer tipo de desigualdade injustificada deve ser mitigada pela ação estatal. Nesse sentido, o sistema de discriminação positiva das políticas de ação afirmativa é uma medida perfeitamente justificável, vez que o objetivo é alcançar aqueles que estão em desprivilegio no acesso a bens e direitos.

\section{Desigualdades e Justiça Social, entre Critérios Sociais e Multiculturais}

As cotas para ingresso na graduação do ensino superior têm como propósito corrigir distorções sociais em três critérios distintos: desigualdade de renda, desigualdade de raça e desigualdade étnica. Trata de uma política de ação afirmativa que reuni um conjunto de informações relevantes para classificar determinados candidatos e lhes oferecer meios mais facilitados de acesso à universidade pública.

Desde logo fica claro tratar-se de um mecanismo que opera por meio de uma forma de discriminação. Essa distinção se faz em razão de características sociais específicas, que ao longo do tempo criaram condições desfavoráveis de acesso à educação formal para indivíduos, identificados por gênero, renda, cor da pele ou grupo étnico. Portanto, estamos diante de uma forma de mitigação das contingências sociais.

Entretanto, é preciso saber quais efeitos o atual sistema de cotas tem produzido para a educação superior. A Lei Federal 12.711/12 reserva 50\% das vagas dos cursos de graduação a candidatos oriundos no ensino médio público. Essa parcela é dividida em duas partes, sendo uma disponibilizada aos candidatos que têm renda per capita de até 1,5 salários mínimos. Por fim, ocorre a distribuição desse total segundo a presença de autodeclarados pretos, pardos, indígenas e pessoas com deficiência, na população cuja instituição de ensino estiver instalada. Os dados colhidos formaram os resultados apresentados a seguir.

O número de estudantes oriundos integralmente do ensino médio de escola pública aumentou expressivamente. A tabela 1 demonstra que em 2015 representavam mais de $64 \%$ de todo contingente estudantil, ao passo que em 2009 esse número era de cerca de $50 \%$. O crescimento foi de $14 \%$ entre esses anos. 
Já em relação à renda, as tabelas 2 e 3 demonstram que houve também um aumento de estudantes com renda per capita menor. As classes C, D e E são a maioria no ensino superior, muito embora esse dado não reflita sua representação na composição social da população.

Quanto ao contexto racial e étnico, as tabelas 4 e 5 apontam autodeclarados pardos e negros elevaram seu grau de participação no ensino superior, muito embora não estejam completamente representados, haja vista sua representação na composição da população brasileira seja ainda maior. Os indígenas, a despeito de diminuírem sua participação, comparado com sua composição social, ainda assim, são considerados os mais representados.

Contudo, devemos ter em mente que antes da Lei 12.711/12 entrar em vigor em 2013, a maior parte das universidades já adotava ações afirmativas com predominância de critério socioeconômico em detrimento do multicultural (CAMPOS, FERES JUNIOR, 2016). Esse fator pode ser considerado uma variável nas constatações que dizem respeito critérios de renda e ensino médio público, mas é pouco expressivo na questão étnico-racial.

Aliás, tendo em vista seu desenho institucional, a Lei 12.711/12 que uniformizou os programas de cotas em todas as universidades federais, privilegiou esse caráter socioeconômico. Essa expressão é constatada quando se toma por primeiro o fato de o candidato ter cursado integralmente o ensino médio em escola pública, e posteriormente dividi as vagas reservadas em dois grupos definidos segundo questões de renda. A legislação subsumiu as vagas destinadas para negros, indígenas e pessoas com deficiência à cota para estudantes do ensino médio público e economicamente carentes.

Um sistema de cotas com critérios étnico-raciais exclusivos poderia trazer resultados mais consistentes, sobretudo quanto à sub-representação desses grupos na estrutura social brasileira. Dados sobre discriminação e desigualdade estão quase sempre relacionados ao racismo velado da população brasileira que foi sendo instituído ao longo de décadas e enraizouse culturalmente. É quase que unânime essa constatação e não traduz nenhuma novidade (MOEHLECKE, 2002).

Entretanto, no campo prático, são várias as controvérsias acerca sobre quais seriam as melhores soluções para atacar esse problema, que se mantem inalterado por anos. Muitos dizem que a escolha mais acertada para o enfrentamento da desigualdade racial e étnica são políticas de cunho social neutro, que leva em conta apenas o critério de renda. Os defensores desse ponto de vista dizem que a população economicamente carente em grande parte encontra-se relacionada aos indivíduos pertencentes a esses grupos e, portanto, bastaria corrigir apenas essa distorção (MOEHLECKE, 2004). 
Porém, as experiências analisadas não permitem assegurar que políticas somente sociais não seriam suficientes para resolver o problema da desigualdade étnico-racial. Isto porque, além da discriminação social, a população desses grupos também sofre com as discriminações de cunho racial, em maior grau na representação de posições de liderança e prestígio na sociedade. Nesse sentido, as propostas não são excludentes, ambas as medidas deveriam ser complementares, posto que a questão racial é reforçada pelo critério de renda. (MOEHLECKE, 2004).

A luz da teoria de justiça como equidade, as cotas de recorte étnico-racial não são fáceis de justificar, posto que Rawls oferece argumentos díspares para caracterizar quem de fato são os menos favorecidos. Nas primeiras publicações da Teoria da Justiça, diz que os menos favorecidos estariam classificados por critérios de renda e, nesse sentido, a priori, o princípio da diferença não contemplaria quaisquer outras categorias específicas. Entretanto, após uma interpretação mais consistente, levando em conta diferentes publicações ao logo dos anos, é possível justificar a concepção de justiça rawlsiana à defesa das cotas de recorte específico, sem necessariamente estarem atreladas somente à vulnerabilidade socioeconômica. (FERES JUNIOR; CAMPOS, 2013).

Urge mencionar que o público alvo das ações afirmativas pode variar a depender do contexto da estrutura básica social. As disfunções sociais que geram as desigualdades podem caracterizar diferentes atores e contemplar áreas distintas como trabalho, educação e representação política. No Brasil, esse tipo de política tem como característica privilegiar uma perspectiva social, com medidas redistributivas ou assistenciais contra a pobreza (MOEHLECKE, 2002).

A razão dessa característica, talvez, ainda seja resultado dos efeitos provenientes dos mecanismos de reprodução ideológica de valores e princípios que reforçaram a ideia da existência de uma democracia racial ancorada na constatação da existência de um povo mestiço que, consequentemente, negligencia o racismo institucional brasileiro. Decerto, a Lei das Cotas vem promovendo resultados satisfatórios muito embora, ainda, aquém de espelhar integralmente a composição social do país. Dessa forma, é necessário que perdure por mais tempo e também conjugue demais políticas, posto que o processo de efetivação das políticas públicas leva em consideração a integração das variáveis necessariamente ligadas ao modelo que lhe é proposto (LIMA; D`ASCENZI, 2013).

Portanto, para pensar a questão da democratização do ensino superior não é medida suficiente apenas promover o acesso facilitado, mas deve conjugá-lo com demais políticas de 
cunho assistencialista. Para tanto, é necessário pensar em ações pontuais a serem desenvolvidas durante o percurso do graduando na universidade.

\section{Considerações finais}

A despeito de outras políticas de expansão, interiorização e restruturação da educação superior, constatou que a Lei das Cotas de fato vem produzindo resultados consistentes. É perceptível a diminuição de diversos fatores causadores de desigualdades, constituindo um sistema de justiça equitativa, por meio da discriminação positiva, cuja justificativa é o princípio da Diferença na reformulação do segundo princípio de Justiça de Rawls.

Entretanto, o perfil discente que vem se desenhando nesses últimos anos, consequência quase que inequívoca da Lei das Cotas, exige a associação de políticas de foco, pois adentrou nas universidades públicas uma população historicamente excluída e, portanto, diversos desafios, em especial, para as políticas de assistência estudantil.

O princípio da Diferença para operar de maneira efetiva e em plenitude, na concretização da justiça social, não deve apenas prever a discriminação positiva sobre um viés único, que no caso das cotas para o ensino superior almeja somente a questão do acesso sem garantir condições de permanência. As dimensões da desigualdade operam pulverizadas em diversos fatores - não apenas na renda, mas também estão circunscritas em símbolos e valores políticos, e para mitigar essas contingências é necessário pensar em múltiplos contextos.

Por esta razão, a política de cotas sozinha, garantindo apenas o ingresso dessa parcela discriminada da população, não conseguirá a democratização plena. É necessário pensar não apenas em oportunizar o ingresso à graduação, mas também nas circunstâncias para que o estudante cotista tenha condições de usufruir do ambiente acadêmico como qualquer outro, inclusive dando condições para que seja admirado por si e seus colegas, em status de igual respeito e, dessa maneira, tenha a opção de seguir ou não adiante na vida acadêmica.

\section{REFERÊNCIAS}

ASSOCIAÇÃO NACIONAL DOS DIRIGENTES DAS INSTITUIÇÕES FEDERAIS DE ENSINO SUPERIOR- ANDIFES. IV Pesquisa do perfil do socioeconômico e cultural dos estudantes de graduação das instituições federais de ensino superior brasileiras. Uberlândia-MG, 2016. Disponível em: http://www.andifes.org.br/categoria/documentos/biblioteca/publicacoes-andifes. Acesso: 30 maio 2018. 
FERES JR, João.; CAMPOS, Luiz Augusto. Liberalismo igualitário e ação afirmativa: da teoria moral à política pública. Revista de Sociologia e Política. v. 21, n. 48, p. 85-99, Curitiba, 2013. Disponível em: http://revistas.ufpr.br/rsp/article/view/38764. Acesso em: 02 abr. 2018.

FERES JR, João.; CAMPOS, Luiz Augusto. Ação Afirmativa no Brasil: Multiculturalismo ou Justiça Social? Revista Lua Nova, 99, p. 257-293, São Paulo, 2016. Disponível em: http://www.scielo.br/pdf/ln/n99/1807-0175-ln-99-00257.pdf. Acesso em: 20 maio 2018.

LIMA, Luciana Leite Lima.; D'ASCENZI, Luciano. Implementação de Políticas Públicas: Perspectivas Analíticas. Revista de Sociologia e Política, v. 21, n. 48, 2013. Disponível em: http://revistas.ufpr.br/rsp/article/view/38765. Acesso em: 05 maio 2018.

LOVETT, Frank. Uma Teoria da Justiça, de John Rawls. trad. Vinicius Figueira, Edição do Kindle, Penso, Porto Alegre, 2013.

MAYORGA, Claudia.; SOUZA, Luciana Maria de. Ação Afirmativa na Universidade: a permanência em foco. Revista Psicologia Política, v. 12, p. 263-281, São Paulo, 2012. Disponível em: http://pepsic.bvsalud.org/scielo.php?script=sci_arttext\&pid=S1519549X2012000200006. Acesso em: 31 maio 2018.

MOEHLECKE, Sabrina. Ação Afirmativa: História e Debates no Brasil. Cadernos de Pesquisa, n. 117, p. 197-217, nov. 2002. Disponível em:

http://www.scielo.br/pdf/cp/n117/15559.pdf. Acesso em: 20 maio 2018.

MOEHLECKE, Sabrina. Ação Afirmativa no Ensino Superior: Entre a Excelência e a Justiça Racial. Educação e Sociedade: Revista de Ciências da Educação, v. 25, n. 88, p. 757-776, Campinas 2004. Disponível em: http://www.scielo.br/pdf/\%0D/es/v25n88/a06v2588.pdf. Acesso em: 31 maio 2018.

PAIVA, Ana Maria de.; CUNHA, Sarah. Perfil Socioeconômico dos Graduandos das Ifes. Radar, n. 49, fev. 2017. Disponível em:

http://www.ipea.gov.br/radar/temas/educacao/632-perfil-socioeconomico-dos-graduandosdas-ifes. Acesso: 30 maio 2018.

PETRONI, Lucas. O Argumento da estabilidade no contratualismo de John Rawls. Kriterion: Revista de Filosofia. v. 58, n. 136, p. 139-161, Belo Horizonte, 2017. Disponível em: http://www.scielo.br/scielo.php?script=sci_abstract\&pid=S0100512X2017000100139\&lng=en\&nrm=iso\&tlng=pt. Acesso em: 29 abr. 2018.

RAWLS, John. Uma Teoria da Justiça. Trad. Jussara Simões, 4. ed. Martins Fontes, São Paulo, 2016.

SCALON, Celi; SALATA, André. Desigualdades, estratificação e justiça social. Civitas: Revista de Ciências Sociais, v. 16, n. 2, 2016. Disponível em: http://revistaseletronicas.pucrs.br/ojs/index.php/civitas/article/view/24479. Acesso em: 29 abr. 2018.

SILVA, Rafael da. Desenho institucional e promoção da justiça em espaços participativos: implicações em um estudo de caso. Opin. Publica, v. 20, n. 2, Campinas, 2014. Disponível 
em: http://www.scielo.br/scielo.php?script=sci_arttext\&pid=S0104-

$62762014000200252 \& \operatorname{lng}=\mathrm{en} \& \operatorname{lng}=\mathrm{en}$. Acesso em: 29 abr. 2018.

SILVEIRA, Denis Coitinho. Justificação pública: a função da ideia de estrutura básica da sociedade em Rawls. Kriterion: Revista de Filosofia, v. 52, n. 123, p.197-211, Belo Horizonte, 2011. Disponível em:

http://www.scielo.br/scielo.php?script=sci_abstract\&pid=S0100-

512X2011000100011\&lng=en\&nrm=iso\&tlng=pt. Acesso em: 29 abr. 2018.

TREDANARO, Emanuele. A Abordagem contratualista de "A Theory of Justice" entre Método e Objetivos. Algumas Observações a partir das Últimas Críticas de Onora O'Neill. Kriterion: Revista de Filosofia, v. 58, n. 136, p. 65-86, Belo Horizonte, 2017. Disponível em: http://www.scielo.br/scielo.php?script=sci_abstract\&pid=S0100-

512X2017000100065\&lng=en\&nrm=iso\&tlng=pt. Acesso em: 29 abr. 2018.

VASCONCELOS, Mário Sérgio.; GALHARDO, Eduardo. O programa de inclusão na UNESP: valores, contradições e ações afirmativas. Rev. Ibero-Americana de Estudos em Educação. v. 11, n. esp. 1, p. 285-306, 2016. Dossiê: X Encontro Ibero-Americano de Educação, Araraquara, SP, 2016. Disponível em:

https://periodicos.fclar.unesp.br/iberoamericana/article/view/8553. Acesso em: 01 set. 2018.

ZANITELLI, Leandro Martins. Discriminação Privada e o Segundo Princípio da Justiça de Rawls. Kriterion: Revista de Filosofia, v. 56, n. 132, p. 393-411, Belo Horizonte, 2015. Disponível em: http://www.scielo.br/scielo.php?script=sci_abstract\&pid=S0100512X2015000200393\&lng=en\&nrm=iso\&tlng=pt. Acesso em: 28 abr. 2018.

\section{Como referenciar este artigo}

MARTINS, Paulo Fernandes de Melo.; SANTOS, Maurício Dias. As políticas afirmativas no ensino superior e o desenho institucional de justiça como equidade em Rawls. Revista IberoAmericana de Estudos em Educação, Araraquara, v. 14, n. 2, p. 437-455, abr./jun., 2019. EISSN: 1982-5587. DOI: 10.21723/riaee.v14i2.11753

Submetido em: 02/09/2018

Aprovado em: 10/10/2018 